\title{
Study on the Path of Constructing Ecological Poverty Alleviation Model in the Concentrated and Connected Special Poverty Area in Shaanxi Province
}

\author{
Jiaojiao Mo \\ Xi'an Peihua University, Xi’an, Shaanxi, 710125
}

Keywords: Shaanxi Province; the Concentrated and Connected Special Poverty Area; ecological poverty alleviation model; poverty alleviation model

\begin{abstract}
The natural condition is poor, the infrastructure construction is backward in the concentrated and connected special poverty area in Shaanxi Province, the balance point between poverty alleviation and ecological protection is difficult to grasp, the mode of ecological poverty alleviation can realize ecological protection, and it can also solve the deep poverty in the special hardship area of Shaanxi. This paper first expounds the ecological precise poverty alleviation model, then analyzes the current situation of ecological poverty alleviation in the special hardship areas of Shaanxi Province, and analyzes the existing problems of ecological poverty alleviation in the special hardship areas of Shaanxi Province. Finally, it tries to put forward the path of constructing the ecological poverty alleviation model in Shaanxi Province.
\end{abstract}

\section{Introduction}

The formulation of the Concentrated and Connected Special Poverty Areas is gradually formed in the process of poverty alleviation and development in China, which the key word of poverty alleviation in the new period. Due to the geographical conditions and the policy support of public service, there are some Concentrated and Connected Special Poverty Areas in Shaanxi, mainly in Liu Panshan area, Qinba Mountain Area and Lv Liang Mountain area. It is necessary to develop the economy and raise the income level of farmers in the Concentrated and Connected Special Poverty Areas in Shaanxi Province in order to better alleviate poverty, but the fragile ecological environment must not be destroyed. The ecological poverty alleviation model can also realize the ecological protection of the special hardship areas in Shaanxi in order to help the poor. This paper advocates the construction of ecological poverty-alleviation model in the Concentrated and Connected Special Poverty Areas in Shaanxi Province.

\section{The ecological poverty alleviation model}

All departments of the State Council and local governments at all levels should intensify coordination and coordination, concentrate on implementing a number of livelihood projects, vigorously improve production and living conditions, cultivate and expand a number of characteristic superior industries, and speed up the pace of construction of important regional infrastructure. We should strengthen ecological construction and environmental protection, solve the bottleneck problems that restrict development, promote the equalization of basic public services, and fundamentally change the face of the special hardship areas. The ecological poverty alleviation model is a new model of accurate poverty alleviation, which can not only improve the ecological environment, but also improve the living environment of rural areas, but also contribute to the development of local industries, raise the level of industrial development, and create welfare for the local people. 


\section{The Current situation of ecological poverty alleviation in the Concentrated and Connected Special Poverty Areas in Shaanxi Province.}

\subsection{The general situation in the Concentrated and Connected Special Poverty Areas in Shaanxi Province}

The land area of Shaanxi Province is 203,600 square kilometers, which is divided into three parts from north to south: Loess Plateau of Northern Shaanxi, Guanzhong Plain and Qinba Mountains of Southern Shaanxi. The total population is 37.35 million, of which 22.739 million are rural people, with 10 districts, 10 cities, 107 counties (cities and districts), 1,747 towns (street offices) and 27, 888 administrative villages under the jurisdiction of 10 districts and demonstration zones of Yang Ling's agricultural high and new technology industries. There are 8,400 low-income villages with per capita net income below 2000 Yuan in the province, accounting for 130\% of the total number of administrative villages. There are still 5.58 million low-income people in the rural areas, accounting for $20 \%$ of the population in rural village. And the Concentrated and Connected Special Poverty Areas are mainly concentrated in the "three blocks, two lines", namely, "three blocks": the White Mountains of Northern Shaanxi, the Dead Stone Mountain Areas along the Yellow River coast, the in the middle and high mountain areas of Qinba of Southern Shaanxi, and the "two lines": Guanzhong along the north cage of the Qinling Mountains and the early belt of Weibei.

\subsection{The development of characteristic industry the Concentrated and Connected Special Poverty Areas in Shaanxi Province}

Poor-stricken areas rely on their own natural resources and adhere to market orientation, and Qinba Mountain region forms a special industrial belt with tea, live pigs, edible fungi, rapeseed, citrus, Chinese herbal medicine, sericulture, characteristic forest products and ecological fishery. Wellcome rich selenium-rich agricultural products, Taibai Alpine vegetables and other brand awareness further improved; Liupan Mountain area has formed a characteristic industrial belt with dwarfed apples, dairy animals, facilities and vegetables. The area of dwarfed apples is more than 200,000 mu, which has become the largest demonstration base of dwarf apples in China. Lv Liang mountain area formed with small grain, meat sheep, jujube and photovoltaic industry as the main characteristics of the industrial belt, famous and small miscellaneous grain, Hengshan mutton, Northern Shaanxi white cashmere goat is well known at home and abroad; Baiyu mountain area formed with potato, mountain apple, meat sheep, high efficiency facilities vegetable as the main characteristic industrial belt, potato industry income accounted for $27 \%$ of the income of farmers, become a pillar industry to promote poverty alleviation and income increase among poor households; a special industrial belt with apple, jujube, high-efficiency facilities, beef cattle, fishery, walnut and photovoltaic industry is formed in the earth-rock mountainous area along the Yellow River,. The base of fruit and vegetable is beginning to take shape at the time of millions mu of high quality apples and 1 million mu of facilities. According to statistics, the total output of fruits, vegetables, meat, eggs and milk reached 7.945 million tons, 7.481 million tons, 672,000 tons, 319,000 tons, 626,000 tons in the poverty-stricken areas of Shaanxi Province in 2015 respectively, the characteristic industry benefit is remarkable, has driven the farmer to lift out of poverty to increase the income powerfully.

\section{The problems of ecological poverty alleviation the Concentrated and Connected Special Poverty Areas in Shaanxi Province.}

There are many problems in the construction of ecological poverty alleviation model in the Concentrated and Connected Special Poverty Areas in Shaanxi Province: the infrastructure construction lags behind, the support ability of industry science and technology is low, the chain of industry is not extended long, the competitiveness of characteristic industry is not strong, the level of industry information is not high, and so on. 


\subsection{The infrastructure construction lags behind}

Due to many reasons, such as history, nature, and so on, the poor areas in Shaanxi have more historical debts for infrastructure construction, fewer targeted engineering projects, weak infrastructure for irrigation and water conservancy, frequent natural disasters, frequent occurrence and recurrence. The situation of agriculture "relying on heaven to eat" has not yet been fundamentally changed. The development of ecological poverty alleviation infrastructure in the Concentrated and Connected Special Poverty Areas in Shaanxi Province is poor and needs a lot of investment to perfect the infrastructure construction.

\subsection{The support ability of industry science and technology is low}

The traditional agricultural development mode is the main mode in the Concentrated and Connected Special Poverty Areas in Shaanxi Province, the scale of agricultural production is low, the level of agricultural science and technology is not high, and it is difficult to support the transformation and upgrading of industry. Most of in the Concentrated and Connected Special Poverty Areas in Shaanxi Province are located in mountainous areas, with fragmented plots, low land circulation rates, small scale of operation, low scientific and cultural quality of workers, low conversion rate of science and technology, and extensive production and management methods. Land productivity and labor productivity are low, affected the growth of farmers' income.

\subsection{The chain of industry is not extended long}

The agricultural development of in the Concentrated and Connected Special Poverty Areas in Shaanxi Province mainly consists of planting and breeding. The deep agricultural processing is relatively small, and the brand construction of characteristic agricultural products is lacking. As a result, the industrial chain of the special hardship areas in Shaanxi is relatively short. There are outstanding problems in the industrial structure. Agricultural production still continues its traditional way to a large extent, is still in the stage of direct selling of raw materials, the possibility of the extension of the industrial chain is small, it is unable to improve the added value of agricultural products, and the way of processing agricultural products is extensive. The combination of primary, second and third industries are poor, so it is impossible to construct modern agricultural system.

\subsection{The competitiveness of characteristic industry is not strong}

The industrialization level of the Concentrated and Connected Special Poverty Areas in Shaanxi Province is low, and the competitiveness of the products is not strong. Some poor areas have not formed the core competitiveness of characteristic industries and industrial clusters, market share is low. The number of leading enterprises is small, the scale is small, the mechanism of interest connection with farmers is not close, the ability of cooperative driving industry development is not strong.

\subsection{The level of industry information is not high}

The product market of the Concentrated and Connected Special Poverty Areas in Shaanxi Province is not perfect and the degree of industry informatization is low. The asymmetric information of supply and demand of characteristic products results in the poor circulation of products and the blindness and limitation of farmers' production and management activities. Some places have the characteristic industry resources, but did not build the famous brand, the benefit is not obvious, did not realize the high quality and the high price.

\section{The path of constructing Ecological poverty alleviation Model in the Concentrated and Connected Special Poverty Areas in Shaanxi Province}

The Concentrated and Connected Special Poverty Areas in Shaanxi Province should construct an ecological poverty alleviation model in order to improve the level of agricultural production, vigorously develop green agriculture, develop rural tourism, enhance the competitiveness of 
characteristic industries, and raise the scientific and technological content of agricultural production. It can also promote industrial convergence and, more importantly, protect the ecological environment and achieve sustainable development.

\subsection{To vigorously develop green agriculture}

The Concentrated and Connected Special Poverty Areas in Shaanxi Province have blue sky, clear water, clean air, better soil environmental quality, less industrial pollution, less crop diseases and pests, and superior producing area environment are green and organic on the whole. The non-pollution characteristic product has provided the good condition. We need to pay attention to ecology, vigorously develop green agriculture, based on regional resource carrying capacity, strictly observe the red line of ecological protection, prevent over-exploitation, develop resource-saving, environment-friendly, and eco-conservation industries. The sustainable development of characteristic industries in poor areas can be realized by ensuring the coordination between production development and ecological protection, improving the utilization rate of resources, developing green, organic and non-pollution characteristic products.

\subsection{To develop rural tourism}

Most of the Concentrated and Connected Special Poverty Areas in Shaanxi Province are located in mountainous areas, which have unique natural ecological resources, superior ecological and humanistic conditions, rich red tourism resources, and have the resources to develop rural tourism. We can dig into the historical and cultural resources and the red tourist resources of the special hardship areas in Shaanxi, make use of the pastoral style, highlight the characteristics of each region, create a brand new rural tourism model, and develop agriculture for planting, picking and leisure sightseeing in agriculture. The development of humanistic tourism and characteristic tourism forms the obvious advantage of rural tourism in the Concentrated and Connected Special Poverty Areas in Shaanxi Province.

\subsection{To enhance the competitiveness of characteristic industries}

Efforts will be made to cultivate the dominant and characteristic industries in the special hardship areas of Shaanxi, to develop the industrial chain, to make full use of resource endowments, market conditions, and to develop in depth the characteristics of agriculture, such as building tea, live pigs, Chinese medicinal materials, and forest products in the Qinba Mountains. Ecological fishery and other characteristic industrial bases, adhere to "systematic thinking, industrial chain development," tap the potential for increasing agricultural income, accelerate the level of agricultural modernization, improve the efficiency and characteristics of agricultural production, and enhance the competitiveness of characteristic industries, so as to realize the development model of Shaanxi continuous slice special-hardship region industry.

\subsection{To raise the scientific and technological content of agricultural production}

It is necessary to respect the law of market, adapt to the change of supply and demand, and make the supply of characteristic products more abundant in quantity and more suitable for consumer demand in variety and quality, to persist in scientific and technological innovation, to improve the quality of farmers in the special hardship areas of Shaanxi Province, to strengthen their scientific and technological training, and to vigorously cultivate modern professional farmers can apply scientific and technological technologies to agricultural production and improve the level of mechanization of agricultural production, attaching importance to the development of intelligent agriculture, accelerating the transformation of the mode of industrial development, strengthening the new motive force of innovation and driving development, promoting agriculture can reduce the cost and raise the level of agricultural development.

\section{Conclusion}

To sum up, the ecological poverty alleviation model the Concentrated and Connected Special 
Poverty Areas in Shaanxi Province needs to make full use of the resource endowment conditions under the national strategy of precision poverty alleviation, adhere to the concept of green and ecological, and build a sound mechanism for poverty alleviation with special industries. The poverty-stricken households should share the benefits of various links of the industrial chain to the maximum extent, promote the rich development with the development of green and ecological industry, and form a new pattern of ecological poverty alleviation.

\section{Acknowledgments}

Fund project: This article belongs to the stage achievement of 2018 Shaanxi Social Science Foundation Project, the project name: On the Ecological Poverty Alleviation Model and Realization Mechanism of the Concentrated and Connected Special Poverty Area in Shaanxi Province; project No.: 2018S13

\section{References}

[1] Qian Li. A Study on the Construction of Financial Precision Poverty Alleviation Model in Shaanxi Ankang-Qinba [J]. Inner Mongolia Coal Economy, 2018 (3): 90-91

[2] Li Xiane, Li Qian. Analysis on the characteristics of Poverty and the Interactive Mode of Ecological Protection and Poverty Alleviation in Qinba Area [J]. Agricultural Modernization Research, 2013, 34 (4): 408-411.

[3] Group of Sichuan Provincial Economic Society. A New Path to Alleviate Poverty Accurately in Green Poverty Area [J]. Contemporary County Economy, 2017 (5): 14-17.

[4] Beijing Normal University, China Poverty Alleviation Research Center, Zhang Qi. Analysis and suggestion of Green Poverty reduction Index in the South of Daxing'ling Mountains and other Special Poverty areas [J]. Economic Research Reference, 2017 (7): 3-20.

[5] Zheng Ruiqiang. Study on the Mechanism of Poverty Enhancement in New Urban-rural relationship and the Optimization of Precision Poverty reduction Mechanism in Special Poverty Area [J]. Financial Science, 2018 (6): 100-109 